\title{
Is physical activity a protective factor against pancreatic cancer?
}

\author{
Kollarova $\mathrm{H}^{1}$, Azeem $\mathrm{K}^{1}$, Tomaskova $\mathrm{H}^{2}$, Horakova $\mathrm{D}^{1}$, Prochazka $\mathrm{V}^{3}$, Martinek $\mathrm{A}^{4}$, Shonova $\mathrm{O}^{5}$, \\ Sevcikova $\mathrm{J}^{1}$, Sevcikova $\mathrm{V}^{1}$, Janout $\mathrm{V}^{1,2}$ \\ Department of Preventive Medicine, Faculty of Medicine and Dentistry, Palacky University Olomouc, \\ Czech Republic. katerina.azeem@upol.cz
}

\begin{abstract}
Objectives: The objective of the study was to analyze an association between selected factors and pancreatic cancer, assuming that knowing the etiology would help influence the incidence of this severe type of cancer through primary prevention. In addition to age, gender, BMI and education, the analysis aimed at assessing occupational and leisure-time physical activities with respect to pancreatic cancer.

Background: In numerous studies, physical activity is reported to be a protective factor against pancreatic cancer. Methods: A case-control study was carried out in three centers in the Czech Republic in 2006-2009.

Results: The study comprised a total of 529 individuals, of which 309 were patients with pancreatic cancer and 220 were controls. Leisure-time physical activity showed a statistically significant inverse association with a crude odds ratio of $0.65(95 \% \mathrm{Cl} 0.45-0.93)$, even after adjustment for other studied factors (OR $=0.63,95 \%$ $\mathrm{Cl}$ 0.43-0.92). Conversely, for occupational physical activity, a positive association was only suggested.

Conclusions: Leisure-time physical activity is a protective factor against the development of pancreatic cancer. Occupational physical activity was not confirmed as a protective factor against pancreatic cancer (Tab. 4, Fig. 1, Ref. 22). Text in PDF www.elis.sk.

Key words: pancreatic cancer, physical activity, risk.
\end{abstract}

\begin{abstract}
Abbreviations: odds ratio - OR, confidence interval - CI, body mass index - BMI, relative risk - RR.

Pancreatic cancer is one of the most severe and most rapidly spreading cancers. Worldwide, more than 270,000 new cases are reported and more than 260,000 people die of the disease each year, with there being no significant differences in incidence between males and females $(1.05: 1)(1)$. The Czech Republic is among countries with high incidence and mortality rates. In 2009, the absolute number of new cases in this country was 1,968 (976 males and 992 females), and 1,687 persons ( 873 males and 814 females) died of the disease (2). As in other countries, in the Czech Republic there are no differences between male and female incidence rates. When comparing the incidence and mortality rates with those in other countries, the rates in Czech Republic (9/7/100,000, $808 / 100,000$, respectively; world standard) rank second as to inci-
\end{abstract}

${ }^{1}$ Department of Preventive Medicine, Faculty of Medicine and Dentistry, Palacky University Olomouc, Czech Republic, ${ }^{2}$ Department of Epidemiology and Public Health, Faculty of Medicine, University of Ostrava, Czech Republic, ${ }^{3}$ Department of Internal Medicine II - Gastroenterology and Hepatology, University Hospital Olomouc, Czech Republic, ${ }^{4}$ Department of Internal Medicine, University Hospital Ostrava, Czech Republic, and ${ }^{5} \mathrm{De}-$ partment of Gastroenterology, Ceske Budejovice Hospital, Czech Republic

Address for correspondence: K. Azeem, Department of Preventive Medicine, Faculty of Medicine and Dentistry, Palacky University Olomouc, Hnevotinska 3, CZ-775 15 Olomouc, Czech Republic.

Phone: +420.5 .85632662$

Acknowledgements: This work was supported by the Czech Ministry of Health grant no. NR 9029-4/2006. dence (just after Armenia), and third as to mortality (after Hungary and Israel) $(2,3)$. The severity of pancreatic cancer may be illustrated by survival rates which are among the worst, as well as by increasing trends with a two-fold increase in incidence between 1977 and the present time (2). The median survival for pancreatic cancer is only 3-6 months (4). About $95 \%$ of patients die within one year, mostly within 4-8 months of diagnosis. The 5-year survival is less than $1 \%$. In only a small proportion of patients, i.e. in those undergoing radical surgery (about $10-20 \%$ of all cases), the 5 -year survival ranges from $3.4 \%$ to $10 \%$, with a mean of $17-20$ months $(2,5-7)$. Another problem is the early detection of this severe cancer, with only $5 \%$ of cases being detected in stage I and vast majority of cases (more than $50 \%$ ) being detected as late as in stage IV (2).

The initial symptoms of the disease are mostly non-specific, leading to late diagnosis in most pancreatic cancer cases and thus to high mortality rates and rather poor survival. One of the first symptoms is pain which gradually becomes more intense and is often followed by manifestations of organ involvement. Other symptoms include jaundice, loss of appetite, weight loss and development of diabetes. The main problems with this type of cancer associated with limited options for prevention are the lack of screening programs allowing early detection of the disease and limited knowledge of its etiology.

Risk factors usually associated with pancreatic cancer may be either non-modifiable, such as age, gender, hereditary factors or urbanization, and modifiable, such as smoking, nutritional factors, especially excess energy intake and resulting obesity, alcohol consumption, occupational factors (asbestos, pesticides etc.) 
or health status, mainly chronic pancreatitis, cholelithiasis and diabetes mellitus. Factors with a very strong association include smoking, with a relative risk (RR) ranging from 2 to 6 , some occupational factors, with RR of approximately 11 for work with herbicides, and especially chronic pancreatitis, with RR as high as 24 , or diabetes mellitus, with RR as high as 6 . Apart from factors increasing the risk for the development of pancreatic cancer, there are protective factors. In addition to nutritional factors, these include sufficient physical activity, which potentially lowers the risk by as much as $25 \%(8)$.

The objective of this study was to analyze the association between selected factors and pancreatic cancer, assuming that knowing the etiology would help influence the incidence of this severe type of cancer through primary prevention. In addition to age, gender, body mass index (BMI) and education, the analysis aimed at assessing occupational and leisure-time physical activities with respect to pancreatic cancer.

\section{Methods}

This case-control study was carried out in 2006-2009 in three centers - Olomouc, Ostrava and Ceske Budejovice. The study comprised a total of 529 individuals, of which 309 were patients with pancreatic cancer and 220 were controls. The numbers of pancreatic cancer patients and controls in individual centers are shown in Table 1.

The group comprised 303 males and 226 females. Cases were selected in hospitals located in individual centers (University Hospital Olomouc, University Hospital Ostrava and Ceske Budejovice Hospital) among patients newly diagnosed with pancreatic cancer who lived in the particular region. Controls were recruited in collaboration with selected general practitioners to form a population control group. To avoid bias, controls and cases were from the same region. Age, gender and health status were considered. Due to difficulties with recruiting population controls, their number was lower $(71 \%)$ than the number of pancreatic cancer patients. This difference was particularly significant in the Ceske Budejovice region, with controls accounting for only $58 \%$ of the number of cases (Tab. 1). Information was obtained directly from the participants questioned by trained interviewers using a standardized questionnaire. The questionnaire contained questions on lifestyle, including both occupational and leisure-time physical activities, education as a socio-economic factor, and health status. Data for calculating BMI were ascertained for ages 20 and 40, for 2 years prior to the development of the disease (or 2 years prior to the interview in controls), and for the time of the interview. For the analysis itself, current BMI values were used. Physical activity was divided into parts related to either occupation or leisure time. Oc-

Table 1. Cases and controls in individual centers.

\begin{tabular}{lcccc}
\hline Center & Cases & Controls & Total & Cases: controls \\
\hline Olomouc & 72 & 60 & 132 & $1: 0.83$ \\
Ostrava & 64 & 60 & 124 & $1: 0.94$ \\
České Budějovice & 173 & 100 & 273 & $1: 0.58$ \\
\hline Total & 309 & 220 & 529 & $1: 0.71$ \\
\hline
\end{tabular}

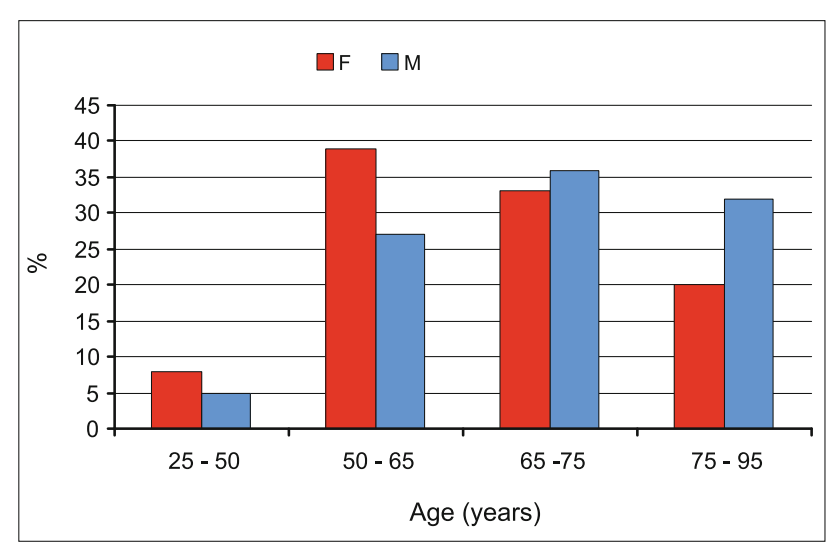

Fig. 1. Age distribution of individuals with pancreatic cancer and control subjects.

cupational physical activity was defined as physical activity lasting at least one hour a week over 1 year or lasting 3 hours weekly for a period of 4 months. The intensity of activity was classified as low, moderate or high based on whether it induced no increase in pulse rate, increased pulse rate and mild sweating, or very high pulse rate and severe sweating, respectively. Leisure-time physical activity was defined as at least 26 hours of physical activity per year, which is 30 minutes weekly over 1 year or 2 hours per week for 3 months. Once again, the intensity of physical activity was assessed using the above criteria. The intensity of physical activity was self-reported by the participants.

The study was approved by the ethics committee of the Faculty of Medicine and Dentistry, Palacky University Olomouc and University Hospital Olomouc. Prior to their enrollment in the study, all participants gave informed consent.

Since the participants chose not to answer some questions, the answer rates for individual characteristics may vary.

To determine the prevalence of the above factors in cases and controls, the crude odds ratio (OR) with a $95 \%$ confidence inter$\mathrm{val}(\mathrm{CI})$ and logistic regression were used. To determine statistical significance, a 5\% significance level was used. Statistical analyses were carried out using the Stata v. 10 software.

\section{Results}

The analysis revealed a statistically significant difference in age depending on gender, with the mean age at disease onset being significantly higher in females (68.9 years) than in males ( 65.4 years). Figure 1 shows the age distribution at diagnosis of pancreatic cancer.

There was no statistically significant difference in the prevalence between males and females despite the ratio of $1.4: 1$ and thus slightly higher prevalence in males. Current BMI values showed a statistically significant difference in males, with male cases having lower BMI values than male controls $(p<0.001)$. Similarly, female cases had lower current BMI than female controls $(\mathrm{p}<0.048)$ which may be explained by the studied type of cancer (Tab. 2). The association between overweight and obesity 
Table 2. BMI values in cases and controls according to gender in the pancreatic cancer study.

\begin{tabular}{|c|c|c|c|c|c|c|}
\hline \multirow{2}{*}{$\begin{array}{l}\text { BMI }\left(\mathrm{kg} / \mathrm{m}^{2}\right) \\
\text { Time }\end{array}$} & \multicolumn{3}{|c|}{ Males - arithmetic mean (SD) } & \multicolumn{3}{|c|}{ Females - arithmetic mean (SD) } \\
\hline & cases $(\mathrm{N}=180)$ & controls $(\mathrm{N}=123)$ & p-value & $\operatorname{cases}(\mathrm{N}=129)$ & controls $(\mathrm{N}=97)$ & $\mathrm{p}$-value \\
\hline Current & $24.68(3.74)$ & $27.89(4.34)$ & 0.000 & $25.91(5.03)$ & $27.25(4.81)$ & 0.048 \\
\hline Two years ago & $27.05(4.16)$ & $27.96(4.35)$ & 0.071 & $28.08(4.79)$ & $27.32(4.72)$ & 0.240 \\
\hline At 20 years & $24.09(2.73)$ & $23.57(2.78)$ & 0.107 & $22.47(3.21)$ & $21.77(2.38)$ & 0.073 \\
\hline At 40 years & $26.51(3.53)$ & $26.00(3.40)$ & 0.216 & $25.48(3.77)$ & $24.49(3.40)$ & 0.044 \\
\hline
\end{tabular}

Table 3. Association between physical activity and other selected factors and the risk for developing pancreatic cancer expressed by crude OR.

\begin{tabular}{|c|c|c|c|c|c|c|}
\hline \multirow{2}{*}{ Risk factor } & \multirow{2}{*}{ Category } & \multirow{2}{*}{$\begin{array}{c}\text { Number } \\
\text { total }\end{array}$} & \multicolumn{2}{|c|}{ Pancreatic cancer } & \multirow{2}{*}{ Crude OR } & \multirow{2}{*}{$95 \% \mathrm{CI}$} \\
\hline & & & cases & controls & & \\
\hline \multirow{4}{*}{$\overline{\text { Age }}$} & $\leq 49$ & 37 & 20 & 17 & $1 *$ & \\
\hline & $50-64.9$ & 177 & 102 & 75 & 1.16 & $0.57-2.36$ \\
\hline & $65-74.9$ & 182 & 111 & 71 & 1.33 & $0.65-2.71$ \\
\hline & $\geq 75$ & 133 & 76 & 57 & 1.13 & $0.55-2.36$ \\
\hline \multirow[t]{2}{*}{ Gender } & male & 303 & 180 & 123 & $1 *$ & \\
\hline & female & 226 & 130 & 97 & 0.95 & $0.65-1.30$ \\
\hline \multirow[t]{2}{*}{ Smoking } & no & 241 & 137 & 104 & $1 *$ & \\
\hline & yes & 280 & 166 & 114 & 1.11 & $0.78-1.57$ \\
\hline \multirow[t]{3}{*}{ BMI } & $\geq 18.5<25 \mathrm{~kg} / \mathrm{m}^{2}$ & 160 & 98 & 62 & $1 *$ & \\
\hline & $\geq 25<30 \mathrm{~kg} / \mathrm{m}^{2}$ & 212 & 121 & 91 & 0.84 & $0.55-1.28$ \\
\hline & $\geq 30 \mathrm{~kg} / \mathrm{m}^{2}$ & 144 & 80 & 64 & 0.79 & $0.50-1.25$ \\
\hline \multirow[t]{3}{*}{ Education } & primary & 96 & 65 & 31 & $1 *$ & \\
\hline & vocational & 185 & 122 & 63 & 0.92 & $0.55-1.56$ \\
\hline & secondary & 163 & 81 & 82 & 0.47 & $0.28-0.80$ \\
\hline \multirow{2}{*}{$\begin{array}{l}\text { Occupational physical } \\
\text { activity }\end{array}$} & no & 185 & 96 & 89 & $1 *$ & \\
\hline & yes & 319 & 190 & 129 & 1.37 & $0.95-1.97$ \\
\hline \multirow{2}{*}{$\begin{array}{l}\text { Leisure-time physical } \\
\text { activity }\end{array}$} & no & 279 & 173 & 106 & $1 *$ & \\
\hline & yes & 210 & 108 & 102 & 0.65 & $0.45-0.93$ \\
\hline \multirow{3}{*}{$\begin{array}{l}\text { Occupational physical } \\
\text { activity - intensity }\end{array}$} & low & 43 & 26 & 17 & $1 *$ & \\
\hline & moderate & 121 & 76 & 45 & 1.10 & $0.54-2.26$ \\
\hline & high & 29 & 19 & 10 & 1.24 & $0.47-3.31$ \\
\hline \multirow{2}{*}{$\begin{array}{l}\text { Leisure-time physical } \\
\text { activity - intensity }\end{array}$} & low & 47 & 21 & 26 & $1 *$ & \\
\hline & moderate and high & 126 & 62 & 54 & 0.70 & $0.36-1.39$ \\
\hline
\end{tabular}

$1 *$ basic category

was analyzed using both the crude and adjusted ORs $(\mathrm{OR}=0.84$ and 0.79 , respectively, and 0.93 and 0.79 , respectively after adjustment). However, no statistically significant association was found (Tabs 3 and 4). Although smoking is considered a causative risk factor for the development of pancreatic cancer, the study failed to confirm the association (crude $\mathrm{OR}=1.11$ ) and this factor was not included in the logistic regression model. When analyzing whether education is related to the development of pancreatic cancer, an inverse association was found in individuals with higher education, with crude ORs of 0.47 (95\% CI $0.28-0.80)$ for secondary education and $0.41(95 \%$ CI $0.22-0.76)$ for tertiary education. When compared with primary education, higher education proved to be a protective factor, as confirmed by adjusting for other studied factors, with values of 0.47 and 0.45 , respectively. Unlike the occupational physical activity, in which a positive association was suggested and the bias was likely due to other occupation-related factors, the leisure-time physical activity showed a statistically significant inverse association and a $35 \%$ decrease in the risk (crude $\mathrm{OR}=0.65,95 \% \mathrm{CI} 0.45-0.93$ ). Even after adjustment for other studied factors $(\mathrm{OR}=0.63 ; 95 \%$ IS $0.43-0.92)$ the result stayed statistically significant. When calculating the crude OR for occupational physical activity, its intensity (low, moderate or high) was taken into consideration. To assess leisure-time physical activity, however, the moderate and high categories of intensity were merged into a single one due to a low number of participants, with no statistical significance. The assessment of leisure-time physical activity in pancreatic cancer patients and controls showed that individuals with pancreatic cancer undertake less physical activity in their leisure time and the difference was statistically significant $(p=0.019)$. The results are summarized in Tables 3 and 4 .

\section{Discussion}

Pancreatic cancer is a disease that most frequently develops at the age of 45-80 years, with the peak incidence in the Czech Republic in the age group of 65-74 years for males and in the age group of 75-79 years for females. In the study group, the mean age was 65.4 years for males and 68.9 years for females, with the difference between genders being statistically significant. Although the mean ages in both males and females were lower than the national peak rates for the incidence of pancreatic cancer, there is an apparent gender difference in age at the onset of this cancer, with females being older than males at the time of diagnosis (2). In the presented study, slightly more males than females were affected by 
Table 4. Association between physical activity and pancreatic cancer risk in the logistic regression model.

\begin{tabular}{|c|c|c|c|c|c|c|c|}
\hline \multirow{2}{*}{ Risk factor } & \multirow{2}{*}{ Category } & \multirow{2}{*}{ Total number } & \multicolumn{2}{|c|}{ Pancreatic cancer } & \multirow{2}{*}{$\begin{array}{l}\text { Adjusted } \\
\text { OR }\end{array}$} & \multirow{2}{*}{$95 \% \mathrm{CI}$} & \multirow{2}{*}{ p-value } \\
\hline & & & cases & controls & & & \\
\hline \multirow[t]{4}{*}{ Age } & $\leq 49$ & 37 & 20 & 17 & $1 *$ & & \\
\hline & $50-64.9$ & 177 & 102 & 75 & 0.82 & $0.37-1.82$ & 0.637 \\
\hline & $65-74.9$ & 182 & 111 & 71 & 1.08 & $0.49-2.38$ & 0.854 \\
\hline & $\geq 75$ & 133 & 76 & 57 & 0.77 & $0.34-1.74$ & 0.537 \\
\hline \multirow[t]{2}{*}{ Gender } & male & 303 & 180 & 123 & $1 *$ & & \\
\hline & female & 226 & 129 & 97 & 0.88 & $0.58-1.32$ & 0.524 \\
\hline \multirow[t]{3}{*}{ BMI } & $\geq 18.5<25 \mathrm{~kg} / \mathrm{m}^{2}$ & 160 & 98 & 62 & $1 *$ & & \\
\hline & $\geq 25<30 \mathrm{~kg} / \mathrm{m}^{2}$ & 212 & 121 & 91 & 0.93 & $0.58-1.47$ & 0.751 \\
\hline & $\geq 30 \mathrm{~kg} / \mathrm{m}^{2}$ & 144 & 80 & 64 & 0.79 & $0.47-1.32$ & 0.368 \\
\hline \multirow[t]{4}{*}{ Education } & primary & 96 & 65 & 31 & $1 *$ & & \\
\hline & vocational & 185 & 122 & 63 & 0.90 & $0.50-1.64$ & 0.736 \\
\hline & secondary & 163 & 81 & 82 & 0.47 & $0.26-0.85$ & 0.012 \\
\hline & tertiary & 82 & 38 & 44 & 0.45 & $0.22-0.90$ & 0.023 \\
\hline \multirow{2}{*}{$\begin{array}{l}\text { Occupational physical } \\
\text { activity }\end{array}$} & no & 185 & 96 & 89 & $1 *$ & & \\
\hline & yes & 319 & 190 & 129 & 1.27 & $0.85-1.91$ & 0.247 \\
\hline \multirow{2}{*}{$\begin{array}{l}\text { Leisure-time physical } \\
\text { activity }\end{array}$} & no & 279 & 173 & 106 & $1 *$ & & \\
\hline & yes & 210 & 108 & 102 & 0.63 & $0.43-0.92$ & 0.018 \\
\hline
\end{tabular}

1 *basic category

pancreatic cancer. According to Olson, this may be due to smoking habits (9). The presented study, however, failed to confirm the association between smoking and higher risk for pancreatic cancer. Similarly, pancreatic cancer was not statistically significantly more frequent in males in the study group. Since pancreatic cancer is strongly age-dependent, the population aging trend will result in an increase in the incidence of pancreatic cancer in the following decades, mainly in countries with longer life expectancy (10).

Obesity is one of the few risk factors conidered to be associated with this type of cancer. Numerous epidemiological studies and meta-analyses have confirmed that the risk mostly ranges from weak to strong association, namely between 1.1 and $2.8(9,11,12)$. Plausible mechanisms of the impact of obesity include inflammatory and hormonal effects of adipose tissue, energy imbalance, and increased exposure to carcinogenic substances due to increased food consumption and lower physical activity (11). Maintaining normal body weight is an adequate means of decreasing pancreatic cancer morbidity and mortality (14). The earlier the overweight or obesity develops, the higher the risk. Rosato et al. found that individuals who were overweight at the age of 30 had an OR of 1.27 (95\% CI, 0.91-1.78) (15). This study, however, failed to show the positive association between overweight or obesity and higher risk for pancreatic cancer. Increased body weight between early adulthood and old age is also associated with a higher risk for the development of pancreatic cancer $(9,13)$. Although such an increase was observed in this study, there were no differences between the cases and controls.

Education and housing are considered to be factors allowing the assessment of the socio-economic status. Especially the level of education significantly influences the socio-economic status of both individuals and entire families as well as their hierarchy of values and behavior. After completion of studies, the level of education no longer changes and it therefore cannot be affected by potential deterioration of health in adulthood (16-18). Results of the study showed protective effects in individuals with second- ary or tertiary education, with the risk being decreased by more than $50 \%$.

The association between the physical activity and the risk for developing pancreatic cancer is not consistently reported in studies. The analysis included both occupational physical activity and leisure-time physical activity, suggesting in the former a positive association but statistically non-significant results affected by confounding occupational factors, rather than by physical activity. Epidemiological studies on the relationship between physical activity and pancreatic cancer risk mostly found an inverse association and risk decrease by $12-37 \%$ (8). In case of occupational activity, this protective effect was not confirmed by the presented study. However, the results may be distorted by lower education, occupational exposure, smoking and other factors such as age and gender. Leisure-time physical activity proved to be a significant protective factor, with a risk decrease of $72 \%$. At the same time, $64 \%$ of responders (both cases and controls) described their activity as moderate. According to the Second Expert Report published by the World Cancer Research Fund in 2007, excess body weight increases the risk for developing pancreatic cancer and, therefore, the risk may be decreased by maintaining the weight. Although the results are not consistent, some studies showed an inverse association between physical activity and pancreatic cancer $(19,20)$. Physical activity has been proved to have beneficial effects on metabolic processes as it decreases glucose levels, increases utilization of glucose in the organism, affects lipid profile, positively influences blood pressure and reduces the amount of body fat. Regular physical activity is the most important factor in preventing the development of obesity and diabetes in individuals with impaired glucose tolerance. The effect of physical activity is complex, affecting the development of obesity, insulin resistance and diabetes mellitus, i.e. the potential risk factors for pancreatic cancer (20). Physical activity on its own or in combination with dietary modifications decreases the incidence of obesity, which in turn affects the incidence of type 2 diabetes and thus also the 
incidence of pancreatic cancer. Michaud et al. pointed to the protective effect of physical activity against pancreatic cancer with weight reduction, particularly in obese persons (21). Physical activity also decreases DNA damage by increasing the effectiveness of antioxidant enzymes, affects carcinogenesis through glutathione S-transferase, influences cell proliferation and apoptosis, reduces inflammation by strengthening the immune system and suppresses angiogenesis (22). Through physiologically plausible mechanisms, physical activity may contribute to prevention of the development of this type of cancer (19).

\section{References}

1. Ferlay J, Shin HR, Bray F, Forman D, Mathers C, Parkin DM. GLOBOCAN 2008 v2.0, Cancer Incidence and Mortality Worldwide: IARC CancerBase No. 10. Lyon, France: International Agency for Research on Cancer; 2010. Available from: http://globocan.iarc.fr, accessed on $08 /$ January $/ 2013$.

2. Dušek L, Mužík J, Kubásek M, Koptíková J, Žaloudík J, Vyzula R. Epidemiology of Malignant Tumours in the Czech Republic. Masaryk University, Czech Republic, [2005], [cit. 2013-1-08]. http://www.svod.cz. Version 7.0 [2007], ISSN 1802 - 8861.

3. Bosetti C, Bertuccio P, Negri E, La Vecchia C, Zeegers MP, Boffetta P. Pancreatic cancer: overview of descriptive epidemiology. Mol Carcinog 2012; 51 (1): 3-13

4. Kollárová H, Janoutová G, Foretová L, Martínek et al. Rizikové faktory karcinomu pankreatu "The risk factors of pancreatic cancer". Klin Onkol 2006; 6: 287-289.

5. Han SS. Analysis of long-term survivors after surgical resection for pancreatic cancer. Pancreas 2006; 32 (3): 271-275.

6. Leffler J. Karcinom pankreatu 2005 současný stav problematiky diagnostiky a léčby. Inter Med Prax 2005; 7 (7-8): 360-363.

7. Ryska M, Bělina F, Strnad R, Froněk J. Resekční výkon - metoda volby terapie karcinomu pankreatu. Bull HPB Chir 2004; 12: 3.

8. Bao Y, Michaud DS. Physical activity and pancreatic cancer risk: a systematic review. Cancer Epidemiol Biomarkers Prev 2008; 17 (10): 2671-2682.

9. Olson SH, Kurtz RC. Epidemiology of pancreatic cancer and the role of family history. J Surg Oncol 2012; 107 (1): 1-7.
10. Maisonneuve $P$, Lowenfels AB. Epidemiology of pancreatic cancer: an update. Dig Dis 2010; 28 (4-5): 645-656.

11. Bracci PM. Obesity and pancreatic cancer: overview of epidemiologic evidence and biologic mechanisms. Mol Carcinog 2012; 51 (1): 53-63.

12. Urayama KY, Holcatova I, Janout $\mathrm{V}$ et al. Body mass index and body size in early adulthood and risk of pancreatic cancer in a central European multicenter case-control study. Int J Cancer 2011; 129 (12): 2875-2884.

13. Li D, Morris JS, Liu J et al. Body mass index and risk, age of onset, and survival in patients with pancreatic cancer. JAMA 2009; 301 (24): 2553-2562.

14. Genkinger JM, Spiegelman D, Anderson KE et al. A pooled analysis of 14 cohort studies of anthropometric factors and pancreatic cancer risk. Int J Cancer 2011; 129 (7): 1708-1717.

15. Rosato V, Tavani A, Bosetti $C$ et al. Metabolic syndrome and pancreatic cancer risk: a case-control study in Italy and meta-analysis. Metabolism 2011; 60 (10): 1372-1378.

16. Šplíchalová A, Šlachtová H, Fejtková $P$, Tomášková H. Vliv socioekonomických faktorů na zdraví v epidemiologických studiích "Impact of socioeconomic factors on health in epidemiological studies". Hygiena 2007; 52 (2): 51-58.

17. Šplíchalová A, Tomášková H, Šlachtová H. Risk of different selfapproach to health in an industrial city population. Cent Eur J Publ Health 2003; 11 (3): 142-148.

18. Stronks K, Van de Mheen H, Van den Bos J, Mackenbach JP. The Interrelationship between Income, Health and Employment Status. Int J Epidemiol 1997; 26 (3): 592-600.

19. O'Rorke MA, Cantwell MM, Cardwell CR, Mulholland HG, Murray LJ. Can physical activity modulate pancreatic cancer risk? a systematic review and meta-analysis Int J Cancer 2010; 126 (12): 2957-2968.

20. Inoue M, Tsugane S. Insulin resistance and cancer: epidemiological evidence. Endocr Relat Cancer 2012; 19 (5): F1-8.

21. Michaud DS, Giovannucci E, Willett WC, Colditz GA, Stampfer MJ, Fuchs CS. Physical activity, obesity, height, and the risk of pancreatic cancer. JAMA 2001; 286 (8): 921-929.

22. Rogers CJ, Colbert LH, Greiner JW, Perkins SN, Hursting SD. Physical activity and cancer prevention: pathways and targets for intervention. Sports Med 2008; 38 (4): 271-296.

Received February 18, 2013. Accepted March 10, 2014. 